Nuyen, J., Spreeuwenberg, P.M., Dijk, L. van, Bos, G.A.M. van den, Groenewegen, P.P., Schellevis, F.G.

The influence of specific chronic somatic conditions on the care for co-morbid depression in general practice.

Psychological Medicine: 2008, 38(2), 265-277

\begin{tabular}{|l|l|}
\hline Postprint Version & 1.0 \\
\hline Journal website & $\underline{\text { http://journals.cambridge.org/action/displayAbstract?fromPage=online\&aid=16 }}$ \\
\hline Pubmed link & $\underline{\underline{\text { http://WWW.ncbi.nlm.nih.gov/pubmed/17825119 }}}$ \\
\hline DOI & $10.1017 /$ S0033291707001298 \\
\hline
\end{tabular}

This is a NIVEL certified Post Print, more info at http://www.nivel.eu

\title{
The influence of specific chronic somatic conditions on the care for co-morbid depression in general practice
}

J. NUYEN ${ }^{\mathrm{A} 1 \mathrm{~A} 2} \underline{\mathrm{C} 1}$, P. M. SPREEUWENBERG ${ }^{\mathrm{A} 1}$, L. VAN DIJK ${ }^{\mathrm{A} 1}$, G. A. M. VAN DEN BOS ${ }^{\mathrm{A} 3}$ P. P. GROENEWEGEN $^{\text {A1 }}$ AND F. G. SCHELLEVIS ${ }^{\mathrm{A} 1 \mathrm{~A} 4}$

a1 NIVEL, Netherlands Institute for Health Services Research, Utrecht, The Netherlands a2 Trimbos Institute, Netherlands Institute of Mental Health and Addiction, Utrecht, The Netherlands

a3 Department of Social Medicine, Academic Medical Centre, University of Amsterdam, Amsterdam, The Netherlands

a4 Department of General Practice/EMGO Institute, VU University Medical Centre, VU University Amsterdam, The Netherlands

\section{ABSTRACT}

Background Limited information exists on the relationship between specific chronic somatic conditions and care for co-morbid depression in primary care settings. Therefore, the present prospective, general practice-based study examined this relationship.

Method Longitudinal data on morbidity, prescribing and referrals concerning 991 patients newly diagnosed with depression by their general practitioner (GP) were analysed. The influence of a broad range of 13 specific chronic somatic conditions on the initiation of any depression care, as well as the prescription of continuous antidepressant therapy for 180 days, was examined. Multilevel logistic regression analysis was used to control for history of depression, psychiatric co-morbidity, sociodemographics and interpractice variation.

Results Multilevel analysis showed that patients with pre-existing ischaemic heart disease (72.1\%) or cardiac arrhythmia (59.3\%) were significantly less likely to have any depression care being initiated by their GP than patients without chronic somatic morbidity (88.0\%). No other specific condition had a significant influence on GP initiation of any care for depression. Among the patients being prescribed antidepressant treatment by their GP, none of the conditions was significantly associated with being prescribed continuous treatment for 180 days.

Conclusions Our study indicates that patients with ischaemic heart disease or cardiac arrhythmia have a lower likelihood of GP initiation of any care for depression after being newly diagnosed with depression by their GP. This 
Nuyen, J., Spreeuwenberg, P.M., Dijk, L. van, Bos, G.A.M. van den, Groenewegen, P.P., Schellevis, F.G.

The influence of specific chronic somatic conditions on the care for co-morbid depression in general practice.

Psychological Medicine: 2008, 38(2), 265-277

finding points to the importance of developing interventions aimed at supporting

GPs in the adequate management of co-morbid depression in heart disease patients to reduce the negative effects of this co-morbidity.

\section{INTRODUCTION}

Depression is known to be co-morbid with a wide and diverse range of chronic somatic conditions, including heart disease, gastrointestinal, neurological and respiratory conditions (Patten et al. 2005; Nuyen et al. 2006). In general, the presence of co-morbid depression in chronically ill patients is associated with increased symptom burden, additive functional impairment, decreased quality of life and increased health-care use, as well as decreased selfcare and adherence to treatment regimens (Katon, 2003; Stein et al. 2006). Evidence is accumulating that depression co-morbid with chronic somatic disease may be associated with increased mortality, particularly in patients with heart disease and diabetes (e.g. Barth et al. 2004; Zhang et al. 2005). Given the negative impact of co-morbid depression, active treatment of depression among patients with chronic somatic illness is recommended (Whooley \& Simon, 2000; Evans et al. 2005). This approach is further substantiated by recent evidence that depression in somatically ill patients can be treated effectively (Krishnan, 2003; Simon et al. 2005).

Because most depressed patients are cared for in primary care settings, it is important to have knowledge of the primary care management of depression in patients with pre-existing chronic somatic disease. Most primary care-based studies that examined the influence of having chronic somatic disease on depression care used a composite measure of chronic somatic morbidity and found conflicting results (Simon et al. 1995; Sartorius et al. 1996; Nutting et al. 2000; Unützer et al. 2000, 2003). Possible explanations for this discrepancy in findings may include differences in study settings and patient characteristics, focusing on different outcome measures of depression care, and considering different sets of specific conditions to establish a composite measure of chronic somatic morbidity.

There is reason to believe that the relationship between chronic somatic conditions and depression management in primary care varies by type of condition. Having chronic somatic morbidity may influence care for depression in several, not mutually exclusive, ways. A preexisting condition may impede depression management because it exerts a strong competing effect on physicians' limited attention and time (Klinkman, 1997), or because physicians and/or patients erroneously believe that there is little reason to initiate any care for depression because it is a 'normal' consequence of having that illness (Cole et al. 1997), or because physicians are reluctant to prescribe antidepressant drugs because of potential adverse side-effects or drug interactions, or to avoid polypharmacy (Bogner et al. 2006). Alternatively, having a chronic somatic condition may also positively impact depression management because it implicates frequent physician-patient contacts and thus more opportunities for depression care (Kurdyak \& Gnam, 2004). It is likely that the relevance of each of the mechanisms described above varies by type of condition, and therefore differential effects of specific chronic somatic conditions on depression care are expected.

However, to the best of our knowledge, only two primary care-based studies have looked at the impact of individual chronic somatic conditions. Bogner et al. (2006) investigated the role of cardiovascular conditions and found that older primary care patients with heart failure had a significantly lower likelihood of receiving 'active' management for depression (i.e. receiving counselling/supportive listening, referred to a mental health specialist, or prescribed psychotropic medication) than those without heart failure. Other types of cardiovascular disease were not significantly related to depression management. An earlier study by Dunn et al. (1999) indirectly suggests no large differential effects of chronic fatigue syndrome, cancer, coronary heart disease, stroke, diabetes and fibromyalgia on 'adequate' duration of antidepressant treatment (i.e. prescribed at least 120 days of antidepressant 
Nuyen, J., Spreeuwenberg, P.M., Dijk, L. van, Bos, G.A.M. van den, Groenewegen, P.P., Schellevis, F.G.

The influence of specific chronic somatic conditions on the care for co-morbid depression in general practice.

Psychological Medicine: 2008, 38(2), 265-277

therapy at an adequate daily dose within the first 6 months after initiation of therapy) in general practice patients aged 18 years or older.

The aim of the present prospective study was to examine the influence of specific chronic somatic conditions on the management of newly diagnosed episodes of depression in general practice. Unlike previous research, this study considered a broad range of conditions and was not restricted to older patients. The following two research questions were addressed: (1) What is the influence of specific chronic somatic conditions on the initiation of any depression care in patients newly diagnosed with depression by their general practitioner (GP)? (2) Among the patients being prescribed antidepressants by their GP, what is the influence of these specific conditions on prescription of continuous antidepressant treatment?

\section{METHOD}

\section{Study setting}

Morbidity, drug prescription and referral data were extracted from the electronic medical record systems of 103 GPs working in 60 practices. These data were collected within the framework of the second Dutch National Survey of General Practice (DNSGP-2; Westert et al. 2005) and the National Information Network of General Practice (LINH, 2006). The DNSGP-2 was a nationwide study of morbidity and interventions in general practice in The Netherlands carried out in 2001. Established in 1992, the LINH database holds longitudinal data on morbidity, prescribing and referrals from participating general practices. The LINH data served as the 'backbone' of the DNSGP-2. Because the 60 practices took part in the DNSGP-2 and continued participation in the LINH, follow-up data were available after the end of the 1-year DNSGP-2 study period, allowing us to examine depression care provided by GPs during a 1-year period after they had diagnosed a depression.

Morbidity data comprised: (1) diagnoses made during contacts with a patient, and (2) diagnoses of all relevant health problems of a patient, including those developed in the past, recorded on a so-called 'problem list' (Metsemakers et al. 1992). Diagnoses were coded according to the International Classification of Primary Care (ICPC; Lamberts \& Woods, 1987) based on the criteria of the International Classification of Health Problems in Primary Care (ICHPC-2-Defined; WONCA Classification Committee, 1983). During the contact registration, GPs recorded whether a health problem concerned a new or an ongoing problem and different contacts for the same health problem were clustered into episodes of disease. Prescription records were coded according to the Anatomical Therapeutic Chemical (ATC) classification system (WHO, 2006).

\section{Study population}

The total practice population registered with the 60 practices $(n=236829)$ in 2001 was representative of the Dutch population in terms of age, gender and type of health-care insurance.

Potential participants were patients who were diagnosed at the age of 18 years or older with a new episode of depression (ICPC code P76) during the 1-year contact registration of the DNSGP-2 ( $n=1110)$. The ICHPPC-2-Defined criteria for depression correspond largely to those of the DSM-IV for major depression (Van den Akker et al. 2004). To ensure that new depressive episodes were investigated, patients were required not to have received a prescription for any antidepressant (ATC code N06A) or lithium (code N05AN01) nor to have been referred to a mental health specialist in the 3 months before depression diagnosis. Patients who died during the 1-year follow-up study period $(n=26)$ and those who were no longer registered with the same practice at the end of the study period (e.g. because of moving, nursing home admission; $n=83$ ) were excluded.

The total study population ( $n=991)$ was used to answer the first research question concerning initiation of any depression care in the year following depression diagnosis. The second research question on prescription of continuous antidepressant therapy was examined 
Nuyen, J., Spreeuwenberg, P.M., Dijk, L. van, Bos, G.A.M. van den, Groenewegen, P.P., Schellevis, F.G.

The influence of specific chronic somatic conditions on the care for co-morbid depression in general practice.

Psychological Medicine: 2008, 38(2), 265-277

using a subset of this population, namely the patients who received at least one prescription for an antidepressant during the study period $(n=790)$. To ensure that antidepressant treatment provided by GPs was investigated, we excluded patients who received a prescription for lithium and/or were referred to a mental health specialist during the study period ( $n=93$ ). In addition, 30 patients were excluded because either the first antidepressant drug was prescribed 180 days or more after depression diagnosis or because specific prescription data were missing, leaving a study population of 667 patients to examine continuity of antidepressant treatment.

\section{Dependent variables}

Any depression care was considered to be initiated following depression diagnosis if the patient received at least one prescription for any antidepressant or lithium, and/or was referred at least once to a mental health professional for depression, and/or had at least one follow-up face-to-face contact for depression with their GP within 4 weeks after diagnosis. The last part of our definition was incorporated to ensure that patients were included whose depression was being managed by a GP by means of a (short-term) psychological intervention or a 'watchful waiting' approach.

To measure prescription of continuous antidepressant treatment, a 'continuous multipleinterval measure of medication availability’ (CMA) was used (Steiner \& Prochazka, 1997). This measure represents the sum of the days covered by all prescriptions in a specific period divided by the total number of days during the specified period, and can potentially range from $0 \%$ to values exceeding $100 \%$ (in case of oversupply). The number of days covered by each prescription was estimated by multiplying the quantity of a drug prescribed by its corresponding defined daily dose (DDD). The DDD is the assumed average maintenance dose per day for a drug used for its main indication in adults (WHO, 2006). Subsequently, for each patient, a CMA score for a 180-day period was calculated and used to define

presence (CMA $\quad 80 \%)$ or absence $(\mathrm{CMA}<80 \%)$ of being prescribed continuous antidepressant therapy. A 180-day period was examined because clinical practice guidelines for the treatment of depression (e.g. Anderson et al. 2000; APA, 2000), including the guideline of the Dutch College of General Practitioners (Van Marwijk et al. 2003), recommend continuing antidepressant treatment for at least 6 months after remission. A CMA cut-off score of $80 \%$ is used conventionally to define a treatment episode as continuous or discontinuous based on prescription data (Katon et al. 2005).

\section{Independent variables}

The primary independent variable of interest was having a specific chronic somatic condition at the time of newly diagnosed depression. Diagnoses recorded during patient contacts, as well as diagnoses recorded on the problem lists, were used to identify patients with pre-existing specific chronic conditions. Thirteen conditions were studied because they are highly prevalent in general practice and/or known to be frequently co-morbid with depression (Patten et al. 2005; Nuyen et al. 2006) (see Appendix for a description of the included diagnoses): colon conditions, stomach/duodenal conditions, hypertension, cardiac arrhythmia, ischaemic heart disease, osteoarthritis/rheumatoid arthritis, migraine, neurological disease, chronic lung conditions, skin conditions, diabetes mellitus, thyroid conditions, and cancer. In addition, by considering a comprehensive range of other diagnoses of possible chronic somatic conditions (see Nuyen et al. 2006), a broad and heterogeneous category of 'any other chronic condition' was established. Patients were defined as having no chronic somatic morbidity if they were not diagnosed with any of the conditions considered.

Other variables were taken into account that could potentially influence depression care, including history of a previous depressive episode, psychiatric co-morbidity, and sociodemographic variables (age, gender, highest educational level attained) (Kessler et al. 
Nuyen, J., Spreeuwenberg, P.M., Dijk, L. van, Bos, G.A.M. van den, Groenewegen, P.P., Schellevis, F.G.

The influence of specific chronic somatic conditions on the care for co-morbid depression in general practice.

Psychological Medicine: 2008, 38(2), 265-277

2003). A prior depressive episode was considered to have occurred when a patient had a depression diagnosis on their problem list. The presence of co-existent psychiatric morbidity at the time of depression diagnosis was derived from diagnoses recorded during the contact registration and those recorded on the problem lists. Two categories were formed: co-morbid anxiety disorder and other psychiatric co-morbidity (i.e. substance abuse disorder, schizophrenia/other psychotic disorder, or other mental disorder). Age was categorized into

five groups (18-24, 25-44, 45-64, 65-74 and 75 years) and educational level into three [low (none or elementary school), middle (high school) and high (college or university)]. A separate category of missing educational data was created because the attained level of education was unknown for a substantial number of patients (23.9\%).

\section{Statistical analysis}

Multilevel logistic regression analysis using MLwiN version 2.0 was carried out to examine the first research question on the association between specific chronic somatic conditions and initiation of any depression care. Multilevel analysis was used because the data had a two-level hierarchical structure (practice level and patient level) and allowed us to adjust for variation due to differences between general practices. A random intercept logistic model was used, yielding the odds of initiation of any depression care for each group of patients with a specific chronic somatic condition compared to patients without chronic somatic morbidity, controlling for the potential influence of the measured covariates as well as interpractice variation. Parameters were estimated using the second-order predictive quasilikelihood procedure with extra-binomial variation at level one (Goldstein, 1995).

The second research question regarding prescription of continuous antidepressant therapy was addressed in a similar way. Sensitivity analyses were conducted to test whether the results concerning continuous prescription were robust to using a more (90\%) or a less (70\%) stringent CMA threshold value.

Of note, as both initiation of any depression care and continuous antidepressant prescription are common outcomes, the odds ratio estimated by logistic regression may substantially overestimate the relative risk. To prevent misinterpretation of odds ratios as meaning the same thing as relative risks in our study, regression coefficients and their confidence intervals are presented.

\section{RESULTS}

\section{Initiation of depression care}

The study sample of 991 patients with a new episode of depression had a mean age of 49.0 years (S.D.=16.9, range $=18-93$ years) at the time of depression diagnosis and $66.7 \%$ of the patients were female. Table 1 shows that 648 patients $(65.4 \%)$ had pre-existing chronic somatic morbidity, with hypertension (18.8\%) being the most prevalent specific chronic condition and migraine (3.5\%) the least prevalent. Table 1 further presents the clinical and sociodemographic characteristics of the total groups of patients with and without chronic somatic illness.

\section{[TABLE 1]}

The unadjusted rate of initiation of any depression care in the year after depression diagnosis by each characteristic is shown in Table 2. Also shown are the unadjusted rates for the three measured 'types' of depression care. Overall, $86.6 \%$ of the patients received any care for depression. Of these 858 patients, $81.5 \%$ were prescribed an antidepressant or lithium, 3.3\% were referred to a mental health professional, and $10.6 \%$ received both types of care. Forty patients (4.6\%) were neither prescribed antidepressants nor referred but had at least one face-to-face contact with their GP for depression within 4 weeks of diagnosis. In $85.8 \%$ of the patients with chronic somatic morbidity, management of depression was 
Nuyen, J., Spreeuwenberg, P.M., Dijk, L. van, Bos, G.A.M. van den, Groenewegen, P.P., Schellevis, F.G.

The influence of specific chronic somatic conditions on the care for co-morbid depression in general practice.

Psychological Medicine: 2008, 38(2), 265-277

initiated, a slightly lower percentage than among the patients without chronic somatic disease (88.0\%). The unadjusted rate of initiation of any depression care varied by type of condition, ranging from $59.3 \%$ for patients with cardiac arrhythmia to $92.7 \%$ for patients with a thyroid condition.

\section{[TABLE 2]}

From the multilevel logistic analysis we learned that, as compared to patients without chronic somatic illness, patients with ischaemic heart disease or cardiac arrhythmia were significantly less likely to receive any depression care from their GP following a diagnosis of new depressive episode (Table 2, last two columns). The odds of initiation of any depression care tended to be decreased for patients with migraine ( $p=0.078)$.

\section{Prescription of continuous antidepressant treatment}

The mean age at the time of depression diagnosis of the 667 patients being prescribed antidepressant therapy was 50.3 years (S.D. $=16.9$, range $=18-90$ years) and $65.7 \%$ were female. Table 3 shows the characteristics of the sample by presence and absence of chronic somatic morbidity. Among the 437 (65.5\%) patients with pre-existing chronic illness, hypertension (19.0\%) was the most common specific condition and cardiac arrhythmia (2.7\%) the least common.

\section{[TABLE 3]}

Overall, 37.8\% of the patients were prescribed continuous antidepressant therapy for 180 days. As shown in Table 4, the unadjusted proportion of patients with continuous antidepressant prescription was somewhat lower in the group with chronic somatic morbidity (37.1\%) than in the group without chronic somatic morbidity (39.1\%). The unadjusted rate of being prescribed continuous therapy for 180 days differed according to type of condition. Patients with cardiac arrhythmia showed the highest rate of continuous prescription (50.0\%), whereas the lowest rate was found among patients with a thyroid condition (23.3\%).

\section{[TABLE 4]}

Subsequent multilevel logistic regression analysis did not reveal a significant influence of any specific chronic somatic condition on continuous prescription of antidepressant therapy (Table 4, last two columns). Sensitivity analyses using a more (90\%) or a less $(70 \%)$ stringent CMA cut-off score to define being prescribed continuous treatment revealed basically the same results as using the conventional threshold of $80 \%$. Only patients with thyroid disease were found to be significantly less likely than patients without chronic somatic morbidity to have been prescribed continuous antidepressant therapy when using a threshold of $70 \%(p=0.022)$.

\section{DISCUSSION}

\section{Principal findings}

The present study indicated that general practice patients with pre-existing ischaemic heart disease or cardiac arrhythmia were less likely than patients without chronic somatic disease to have any depression care being initiated after being newly diagnosed with depression by their GP. No other specific chronic somatic condition impacted significantly on GP initiation of any depression care. Furthermore, among the patients being prescribed antidepressants by their GP, no specific chronic somatic condition was found to have a significant influence on prescription of continuous antidepressant treatment for 180 days. 
Nuyen, J., Spreeuwenberg, P.M., Dijk, L. van, Bos, G.A.M. van den, Groenewegen, P.P., Schellevis, F.G.

The influence of specific chronic somatic conditions on the care for co-morbid depression in general practice.

Psychological Medicine: 2008, 38(2), 265-277

\section{Strengths and weaknesses of the study}

Our study is the first to examine the relationship between specific chronic somatic conditions and depression management in general practice using a nationally representative sample of general practice patients. Unlike previous primary care-based studies (Dunn et al. 1999; Bogner et al. 2006), our study considered a wide range of specific chronic somatic conditions, both initiation of depression care and prescription of continuous antidepressant treatment, and used a study population that was not confined to older patients. Furthermore, besides controlling for several potential confounders at the level of individual patients, including history of depression, psychiatric co-morbidity and sociodemographic characteristics, we adjusted for variation at the practice level by using multilevel modelling.

A number of potential limitations of our study should be considered. First, we relied on data from medical record systems, which may be incomplete. However, it is likely that the completeness of registration of antidepressant drug prescriptions is high because the study was carried out in computerized practices where prescriptions are facilitated by the computer software. Furthermore, to identify patients with chronic somatic morbidity, in addition to diagnoses recorded during patient contacts, diagnoses recorded on problem lists were used, making it unlikely that a substantial number of patients was misclassified as having no (specific) chronic somatic morbidity. Second, the data did not allow us to take into account the severity of specific chronic somatic conditions. Third, the number of patients with a specific chronic condition was sometimes low, which may have limited statistical power to obtain significant results for smaller effects. Fourth, our data did not include direct information on whether a psychological intervention or watchful waiting approach was initiated by the GP after having diagnosed depression. Fifth, the operationalization of being prescribed continuous antidepressant therapy may be criticized. The time period a drug prescription was intended to cover was estimated by using the DDD. The DDD assigned to a drug is nearly always a compromise based on systematic review of the available literature and is not necessarily equal to the actual dose prescribed. Our results regarding continuous prescription should not be biased if the difference between the DDD and the actual prescribed dose did not differ substantially, depending on the presence or absence of (a specific) chronic somatic illness. Sixth, although a CMA threshold value of $80 \%$ is generally used, there is no clear clinical or pharmacological rationale for the appropriateness of this cut-off score (Steiner \& Prochazka, 1997). However, results using different thresholds did not differ substantially from those using the conventional $80 \%$ cut-off score, aside from the finding that patients with thyroid disease were less likely than patients without chronic somatic morbidity to have been prescribed continuous antidepressant treatment for 180 days when using the less stringent threshold of $70 \%$.

\section{Clinical implications and suggestions for future research}

Our finding that general practice patients with ischaemic heart disease or cardiac arrhythmia are less likely to have any care being initiated for newly diagnosed depression is clinically important because the presence of co-morbid depression in patients with heart disease has been found to adversely impact various domains of functioning, quality of life, symptom burden, health-care utilization, self-care and adherence to medical regimens (Katon, 2003; Stein et al. 2006). Furthermore, there is substantial evidence that depression increases the risk of subsequent cardiovascular events and mortality in patients with coronary heart disease or post-myocardial infarction (MI) patients (e.g. Barth et al. 2004; Van Melle et al. 2004). Given the adverse effects of co-morbid depression, an active approach to the management of depression in patients with heart disease is supported, all the more because a growing body of research indicates that concomitant depression with ischaemic heart disease can be effectively and safely treated with selective serotonin reuptake inhibitors (SSRIs) (Roose \& Miyazaki, 2005). Use of SSRIs may even reduce the risk for cardiovascular morbidity and mortality in post-MI patients (Sauer et al. 2001; Taylor et al. 2005). The beneficial influence of antidepressant treatment is further substantiated by a 
Nuyen, J., Spreeuwenberg, P.M., Dijk, L. van, Bos, G.A.M. van den, Groenewegen, P.P., Schellevis, F.G.

The influence of specific chronic somatic conditions on the care for co-morbid depression in general practice.

Psychological Medicine: 2008, 38(2), 265-277

recent naturalistic study demonstrating that primary care patients with ischaemic heart disease and co-morbid depression showed significant improvement in mood, social and emotional functioning, and disability following initiation of antidepressant treatment (Simon et al. 2005). Besides pharmacological treatment, current preliminary evidence suggests that psychological interventions also lead to a reduction in depression, although they appear to have no effect on mortality and non-fatal infarction (Berkman et al. 2003; Rees et al. 2004). Our data did not permit us to identify the mechanism(s) underlying the observed negative effect of having ischaemic heart disease or cardiac arrhythmia on initiation of any depression care. It is possible that heart disease in particular exerts a strong competing effect on GPs' limited attention and time, that co-existent depression in heart conditions is being viewed as a 'natural' reaction not needing active treatment or monitoring, and/or that in heart disease potential adverse side-effects or drug interactions have a strong negative effect on initiating antidepressant therapy. It might be that the well-documented unfavourable cardiovascular profile of tricyclic antidepressants (TCAs) largely explains our findings (Roose \& Miyazaki, 2005). Indeed, in our study, GPs, when initiating antidepressant therapy, infrequently prescribed TCAs to their patients with ischaemic heart disease (8.0\%) or cardiac arrhythmia (8.3\%). However, the relative contraindication for the use of TCAs in patients with heart disease does not seem to be the reason for the observed low rates of initiation of any depression care, as TCAs were also infrequently prescribed for non-chronically ill patients with newly diagnosed depression. Furthermore, we found not only relatively low rates of initiation of any antidepressant drug therapy among the patients with ischaemic heart disease or cardiac arrhythmia but also relatively low rates of referral and having at least one followup face-to-face contact for depression in the 4 weeks following diagnosis (see Table 2). This could suggest that GPs have a relative general 'reservation' about initiating any form of depression care in patients with heart conditions, including watchful waiting. Further research is required to understand the mechanism(s) underlying the relationship between having ischaemic heart disease or cardiac arrhythmia and a lower likelihood of receiving any care for co-morbid depression in general practice.

A number of other suggestions for future research are offered by our study results. Apart from the negative influence of having ischaemic heart disease or cardiac arrhythmia on initiation of any depression care, we observed no other significant impact of specific chronic somatic morbidity on GP management of depression. However, as stated earlier, the lack of other findings may have been due to insufficient statistical power. Further research using larger samples of general practice patients is required to settle this issue. Our finding that initiation of any depression care as well as prescription of continuous antidepressant therapy varied considerably across the various conditions at least indicates that future studies using a composite measure of chronic somatic morbidity need to be aware of the possibility of obscuring meaningful differential effects of specific chronic conditions on depression management.

In our study, we examined depression care routinely provided by GPs, and thus relied on their clinical diagnoses of depression and not on diagnoses based on DSM-IV criteria. Accordingly, the observed rates of depression management were determined by the probability that the GPs diagnosed depression and their decision to initiate some type of depression care. Not addressing diagnosis of depression may give an incomplete picture of the relationship between primary care depression management and specific chronic somatic conditions, because of the possibility that underdiagnosis of depression by GPs may vary by type of condition (Nuyen et al. 2005). Ideally, future research on this relationship should include a validated measure of depression to be able to take into consideration the accuracy of GPs' diagnosis of depression. In addition, including an objective measure of depression severity will allow a detailed investigation of the adequacy of GP management of co-morbid depression. For instance, given the inconclusive evidence for the effectiveness of antidepressants for minor depression (Oxman \& Sengupta, 2002), it would be interesting to 
Nuyen, J., Spreeuwenberg, P.M., Dijk, L. van, Bos, G.A.M. van den, Groenewegen, P.P., Schellevis, F.G.

The influence of specific chronic somatic conditions on the care for co-morbid depression in general practice.

Psychological Medicine: 2008, 38(2), 265-277

know how many chronically ill patients with milder forms of depression are being prescribed antidepressants by their GP and how such treatment practice influences continuity of antidepressant treatment.

Although not the primary focus of this study, it is noteworthy that $15.8 \%$ of the total variance in initiation of depression care and $21.5 \%$ of that in prescription of continuous antidepressant therapy was due to difference between practices, which indicates that general practice characteristics are important determinants of management of depression. Further study is needed to identify and understand GP variation.

\section{CONCLUSIONS}

This study indicates that patients with ischaemic heart disease or cardiac arrhythmia and who are newly diagnosed with co-morbid depression by their GP have a lower likelihood of having any care for depression being initiated by their GP compared with non-chronically ill patients newly diagnosed with depression. This finding points to the importance of developing interventions targeted at supporting GPs in the adequate management of comorbid depression in patients with heart disease to reduce the negative impacts of co-morbid depression and possibly improve outcomes from heart disease. To this end, the mechanisms first have to be ascertained that underlie the decreased likelihood of GP initiation of any depression care in heart disease patients.

\section{ACKNOWLEDGEMENTS}

This study was funded by ZonMw, The Netherlands Organization for Health Research and Development (CZ-TT 2001). 
Nuyen, J., Spreeuwenberg, P.M., Dijk, L. van, Bos, G.A.M. van den, Groenewegen, P.P., Schellevis, F.G.

The influence of specific chronic somatic conditions on the care for co-morbid depression in general practice.

Psychological Medicine: 2008, 38(2), 265-277

\section{TABLES}

Table 1. Characteristics of patients newly diagnosed with depression by their general practitioner according to presence or absence of chronic somatic morbidity

\begin{tabular}{|c|c|c|}
\hline Characteristics & $\begin{array}{l}\text { Patients with chronic } \\
\text { somatic morbidity } \\
(n=648) n(\%)\end{array}$ & $\begin{array}{l}\text { Patients without } \\
\text { chronic somatic } \\
\text { morbidity }(n=343) \\
n(\%)\end{array}$ \\
\hline \multicolumn{3}{|l|}{ Sociodemographic variables } \\
\hline \multicolumn{3}{|l|}{ Gender } \\
\hline Male & $212(32.7)$ & $118(34.4)$ \\
\hline Female & $436(67.3)$ & $225(65.6)$ \\
\hline Mean age (S.D.) & $52.0(17.5)$ & $43.1(13.9)$ \\
\hline \multicolumn{3}{|l|}{ Age group (yr) } \\
\hline $18-24$ & $28(4.3)$ & $25(7.3)$ \\
\hline $25-44$ & $234(36.1)$ & $182(53.1)$ \\
\hline $45-64$ & $213(32.9)$ & $105(30.6)$ \\
\hline $65-74$ & $87(13.4)$ & $22(6.4)$ \\
\hline$\geqslant 75$ & $86(13.3)$ & $9(2.6)$ \\
\hline \multicolumn{3}{|l|}{ Educational level } \\
\hline Low & $139(21.5)$ & $36(10.5)$ \\
\hline Middle & $290(44.8)$ & $165(48.1)$ \\
\hline High & $76(11.7)$ & $48(14.0)$ \\
\hline Unknown & $143(22.1)$ & $94(27.4)$ \\
\hline Previous depressive episode & $143(22.1)$ & $58(16.9)$ \\
\hline \multicolumn{3}{|l|}{ Psychiatric co-morbidity variables } \\
\hline Co-morbid anxiety & $78(12.0)$ & $18(5.2)$ \\
\hline Other psychiatric co-morbidity & $104(16.0)$ & $51(14.9)$ \\
\hline \multicolumn{3}{|l|}{ Type of chronic somatic condition ${ }^{a}$} \\
\hline Hypertension & $122(18.8)$ & \\
\hline Chronic lung & $84(13.0)$ & \\
\hline Skin & $81(12.5)$ & \\
\hline Diabetes mellitus & $58(9.0)$ & \\
\hline Colon & $55(8.5)$ & \\
\hline Stomach/duodenal & $55(8.5)$ & \\
\hline Neurological & $46(7.1)$ & \\
\hline $\begin{array}{l}\text { Osteoarthritis/rheumatoid } \\
\text { arthritis }\end{array}$ & $46(7.1)$ & \\
\hline Ischaemic heart & $43(6.6)$ & \\
\hline Thyroid & $41(6.3)$ & \\
\hline Cancer & $28(4.3)$ & \\
\hline Cardiac arrhythmia & $27(4.2)$ & \\
\hline Migraine & $23(3.5)$ & \\
\hline Any other & $471(72.7)$ & \\
\hline
\end{tabular}

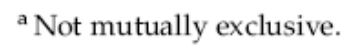


Nuyen, J., Spreeuwenberg, P.M., Dijk, L. van, Bos, G.A.M. van den, Groenewegen, P.P., Schellevis, F.G.

The influence of specific chronic somatic conditions on the care for co-morbid depression in general practice.

Psychological Medicine: 2008, 38(2), 265-277

Table 2. Results regarding initiation of any depression care after being newly diagnosed with depression. Shown are the unadjusted rates of patients receiving any depression care from their general practitioner as well as the rates for the three types of depression care. The last two columns present the results of multilevel logistic regression for initiation of any depression care

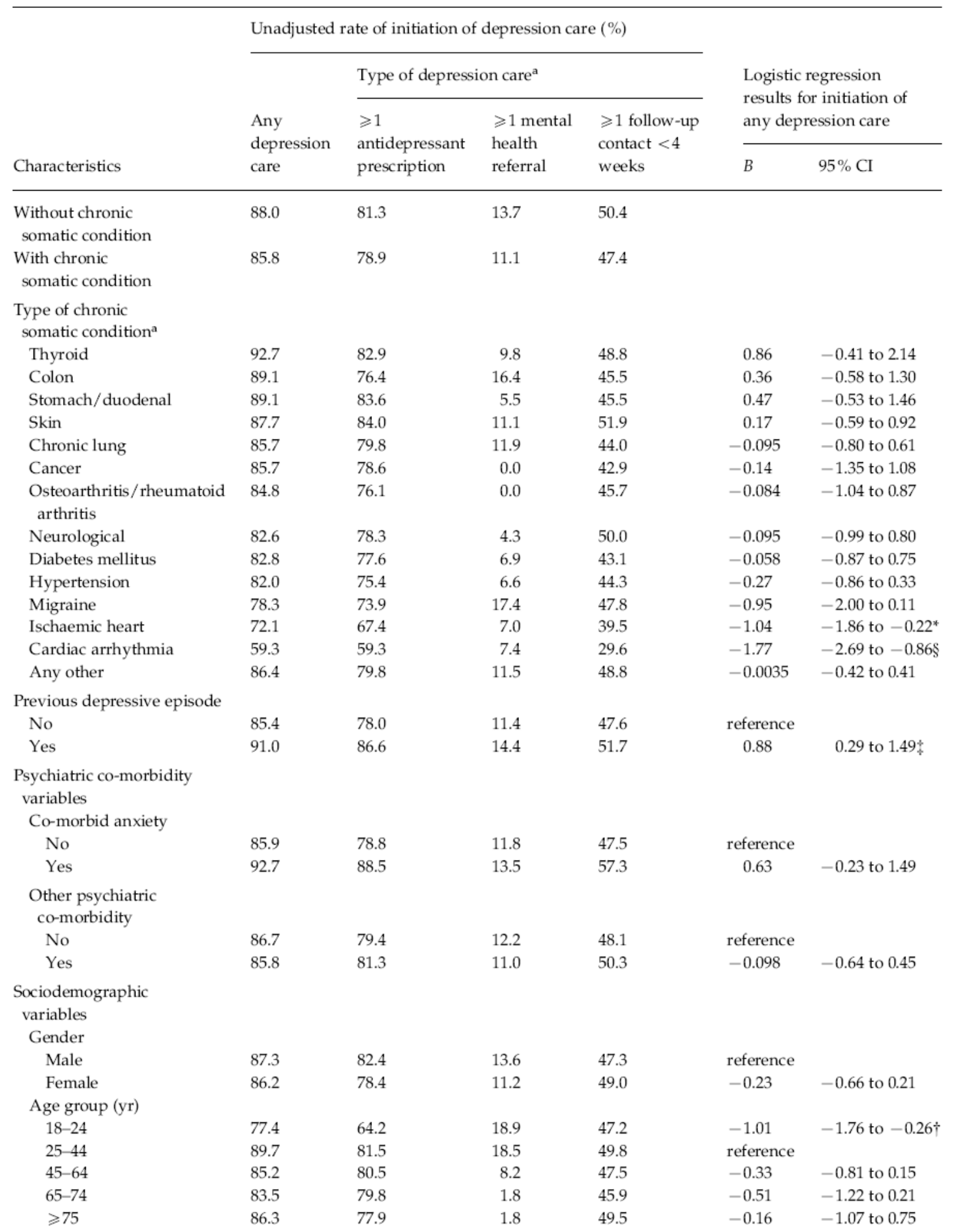


Nuyen, J., Spreeuwenberg, P.M., Dijk, L. van, Bos, G.A.M. van den, Groenewegen, P.P., Schellevis, F.G.

The influence of specific chronic somatic conditions on the care for co-morbid depression in general practice.

Psychological Medicine: 2008, 38(2), 265-277

Table 2 (cont.)

\begin{tabular}{|c|c|c|c|c|c|c|}
\hline \multirow[b]{4}{*}{ Characteristics } & \multicolumn{4}{|c|}{ Unadjusted rate of initiation of depression care (\%) } & \multirow{3}{*}{\multicolumn{2}{|c|}{$\begin{array}{l}\text { Logistic regression } \\
\text { results for initiation of } \\
\text { any depression care }\end{array}$}} \\
\hline & \multirow{3}{*}{$\begin{array}{l}\text { Any } \\
\text { depression } \\
\text { care }\end{array}$} & \multicolumn{3}{|c|}{ Type of depression care ${ }^{a}$} & & \\
\hline & & \multirow{2}{*}{$\begin{array}{l}\geqslant 1 \\
\text { antidepressant } \\
\text { prescription }\end{array}$} & \multirow{2}{*}{$\begin{array}{l}\geqslant 1 \text { mental } \\
\text { health } \\
\text { referral }\end{array}$} & \multirow{2}{*}{$\begin{array}{l}\geqslant 1 \text { follow-up } \\
\text { contact }<4 \\
\text { weeks }\end{array}$} & & \\
\hline & & & & & $B$ & $95 \% \mathrm{CI}$ \\
\hline \multicolumn{7}{|c|}{ Educational level } \\
\hline Low & 89.1 & 81.7 & 7.4 & 50.3 & reference & \\
\hline Middle & 86.8 & 80.9 & 12.5 & 50.1 & -0.55 & -1.19 to 0.080 \\
\hline High & 84.7 & 77.4 & 16.1 & 50.8 & -0.64 & -1.42 to 0.15 \\
\hline Unknown & 85.2 & 77.2 & 12.2 & 42.6 & -0.64 & -1.33 to 0.054 \\
\hline
\end{tabular}

$B$, regression coefficient; $\mathrm{CI}$, confidence interval.

a Not mutually exclusive.

${ }^{*} p<0.05, \uparrow p<0.01, \$ p<0.005, \S p<0.001$ (determined by Wald $\chi^{2}$ tests).

Table 3. Characteristics of patients newly diagnosed with depression by their general practitioner and who are being prescribed antidepressant therapy according to presence or absence of chronic somatic morbidity

\begin{tabular}{|c|c|c|}
\hline Characteristics & $\begin{array}{l}\text { Patients with } \\
\text { chronic somatic } \\
\text { morbidity } \\
(n=437) n(\%)\end{array}$ & $\begin{array}{l}\text { Patients without } \\
\text { chronic somatic } \\
\text { morbidity } \\
(n=230) n(\%)\end{array}$ \\
\hline \multicolumn{3}{|l|}{ Gender } \\
\hline Male & $154(35.2)$ & 75 (32.6) \\
\hline Female & $283(64.8)$ & $155(67.4)$ \\
\hline Mean age (S.D.) & $53.2(17.5)$ & $44.9(14.1)$ \\
\hline \multicolumn{3}{|l|}{ Age group (yr) } \\
\hline $18-24$ & $16(3.7)$ & $12(5.2)$ \\
\hline $25-44$ & $149(34.1)$ & $119(51.7)$ \\
\hline $45-64$ & $145(33.2)$ & $73(31.7)$ \\
\hline $65-74$ & $65(14.9)$ & $19(8.3)$ \\
\hline$\geqslant 75$ & $62(14.2)$ & $7(10.1)$ \\
\hline \multicolumn{3}{|l|}{ Educational level } \\
\hline Low & $103(23.6)$ & $26(11.3)$ \\
\hline Middle & $190(43.5)$ & $112(48.7)$ \\
\hline High & $48(11.0)$ & $30(13.0)$ \\
\hline Unknown & $96(22.0)$ & $62(27.0)$ \\
\hline Previous depressive episode & $104(23.8)$ & $39(17.0)$ \\
\hline \multicolumn{3}{|l|}{ Psychiatric co-morbidity variables } \\
\hline Co-morbid anxiety & $56(12.8)$ & $15(6.5)$ \\
\hline Other co-morbidity & $74(16.9)$ & $33(14.3)$ \\
\hline \multicolumn{3}{|l|}{ Type of chronic somatic condition ${ }^{a}$} \\
\hline Hypertension & $83(19.0)$ & \\
\hline Skin & $58(13.3)$ & \\
\hline Chronic lung & $53(12.1)$ & \\
\hline Stomach/duodenal & $44(10.1)$ & \\
\hline Diabetes mellitus & $38(8.7)$ & \\
\hline Colon & $36(8.2)$ & \\
\hline Osteoarthritis/rheumatoid arthritis & $34(7.8)$ & \\
\hline Neurological & $31(7.1)$ & \\
\hline Thyroid & $30(6.9)$ & \\
\hline Ischaemic heart & $25(5.7)$ & \\
\hline Cancer & $21(4.8)$ & \\
\hline Migraine & $14(3.2)$ & \\
\hline Cardiac arrhythmia & $12(2.7)$ & \\
\hline Any other & $320(73.2)$ & \\
\hline
\end{tabular}

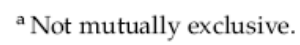


Nuyen, J., Spreeuwenberg, P.M., Dijk, L. van, Bos, G.A.M. van den, Groenewegen, P.P., Schellevis, F.G.

The influence of specific chronic somatic conditions on the care for co-morbid depression in general practice.

Psychological Medicine: 2008, 38(2), 265-277

\section{REFERENCES}

Anderson IM, Nutt DJ, Deakin JF (2000). Evidence-based guidelines for treating depressive disorders with antidepressants : a revision of the 1993 British Association for

Psychopharmacology guidelines. British Association for Psychopharmacology. Journal of Psychopharmacology 14, 3-20.

APA (2000). Practice guideline for the treatment of patients with major depressive disorder (revision). American Psychiatric Association. American Journal of Psychiatry 157 (Suppl. 4), 1-45.

Barth J, Schumacher M, Herrman-Lingen C (2004). Depression as a risk factor for mortality in patients with coronary heart disease: a meta-analysis. Psychosomatic Medicine 66, 802-813.

Berkman LF, Blumenthal J, Burg M, Carney RM, Catellier D, Cowan MJ, Czajkowski SM, DeBusk R, Hosking J, Jaffe A, Kaufmann PG, Mitchell P, Norman J, Powell LH, Raczynski JM, Schneiderman N (2003). Effects of treating depression and low perceived social support on clinical events after myocardial infarction : the Enhancing Recovery in Coronary Heart Disease Patients (ENRICHD) Randomized Trial. Journal of the American Medical Association 289, 3106-3116.

Bogner HR, Ford DE, Gallo JJ (2006). The role of cardiovascular disease in the identification and management of depression by primary care physicians. American Journal of Geriatric Psychiatry 14, 71-78.

Cole SA, Christensen JF, Raju M, Feldman M (1997). Depression. In Behavioral Medicine in Primary Care: A Practical Guide (ed. M. D. Feldman and J. F. Christenson), pp. 177-192. Appleton and Lange: Stamford, CT.

Dunn RL, Donoghue JM, Ozminkowski RJ, Stephenson D, Hylan TR (1999). Longitudinal patterns of antidepressant prescribing in primary care in the UK: comparison with treatment guidelines. Journal of Psychopharmacology 13, 136-143.

Evans DL, Charney DS, Lewis L, Golden RN, Gorman JM, Krishnan KRR, Nemeroff CB, Bremner JD, Carney RM, Coyne JC, Delong MR, Frasure-Smith N, Glassman AH, Gold PW, Grant I, Gwyther L, Ironson G, Johnson RL, Kanner AM, Katon WJ, Kaufmann PG, Keefe FJ, Ketter T, Laughren TP, Leserman J, Lyketsos CG, McDonald WM, McEwen BS, Miller AH, Musselman D, O'Connor C, Petitto JM, Pollock BG, Robinson RG, Roose SP, Rowland J, Sheline Y, Sheps DS, Simon G, Spiegel D, Stunkard A, Sunderland T, Tibbits JR, Valvo WJ (2005). Mood disorders in the medically ill : scientific review and recommendations. Biological Psychiatry 58, 175-189.

Goldstein H (1995). Multilevel Statistical Models. Wiley: New York. Katon W, Cantrell CR, Sokol MC, Chiao E, Gdovin JM (2005). Impact of antidepressant drug adherence on comorbid medication use and resource utilization. Archives of Internal Medicine 165, 2497-2503 Katon WJ (2003). Clinical and health services relationships between major depression, depressive symptoms, and general medical illness. Biological Psychiatry 54, 216-226.

Kessler RC, Berglund P, Demler O, Jin R, Koretz D, Merikangas KR, Rush AJ, Walters EE, Wang PS (2003). The epidemiology of major depressive disorder : results from the National Co-morbidity Survey Replication (NCS-R). Journal of the American Medical Association 289, 3095-3105.

Klinkman MS (1997). Competing demands in psychosocial care. A model for the identification and treatment of depressive disorders in primary care. General Hospital Psychiatry 19, 98-111.

Krishnan KR (2003). Co-morbidity and depression treatment. Biological Psychiatry 53, $701-$ 706.

Kurdyak PA, Gnam WH (2004). Medication management of depression: the impact of comorbid chronic medical conditions. Journal of Psychosomatic Research 57, 565-571.

Lamberts H, Wood W (1987). International Classification of Primary Care (ICPC). Oxford University Press: Oxford. 
Nuyen, J., Spreeuwenberg, P.M., Dijk, L. van, Bos, G.A.M. van den, Groenewegen, P.P., Schellevis, F.G.

The influence of specific chronic somatic conditions on the care for co-morbid depression in general practice.

Psychological Medicine: 2008, 38(2), 265-277

Metsemakers JF, Hoppener P, Knotterus JA, Kocken RJ, Limonard, CB (1992).

Computerized health information in The Netherlands: a registration network of family practices. British Journal of General Practice 42, 102-106.

LINH (Netherlands Information Network of General Practice) (2006). Netherlands Institute for Health Services Research (NIVEL), the Centre for Quality of Care Research (WOK), the National Association of General Practitioners (LHV), the Dutch College of General Practitioners (NHG). (www.linh.nl). Accessed 15 May 2006. Nutting PA, Rost K, Smith J, Werner JJ, Elliot, C (2000).

Competing demands from physical problems: effect on initiating and completing depression care over 6 months. Archives of Family Medicine 10, 1059-1064.

Nuyen J, Schellevis FG, Satariano WA, Spreeuwenberg PM, Birkner MD, Van den Bos GAM, Groenewegen PP (2006). Co-morbidity was associated with neurologic and psychiatric disease: a general practice-based controlled study. Journal of Clinical Epidemiology 59, 1274-1284.

Nuyen J, Volkers AC, Verhaak PF, Schellevis FG, Groenewegen PP, Van den Bos GA (2005). Accuracy of diagnosing depression in primary care : the impact of chronic somatic and psychiatric co-morbidity. Psychological Medicine 35, 1185-1195.

Oxman TE, Sengupta A (2002). Treatment of minor depression. American Journal of Geriatric Psychiatry 10, 256-264.

Patten SB, Beck CA, Kassam A, William JV, Barbui C,Metz LM (2005). Long-term medical conditions and major depression: strength of association for specific conditions in the general population. Canadian Journal of Psychiatry 50, 195-202.

Rees K, Bennett P, West R, Davey SG, Ebrahim S (2004). Psychological interventions for coronary heart disease. Cochrane Database of Systematic Reviews, Issue no. 2,

CD002902.

Roose SP, Miyazaki M (2005). Pharmacologic treatment of depression in patients with heart disease. Psychosomatic Medicine 67 (Suppl. 1), S54-S57.

Sartorius N, Ustun TB, Lecrubier Y, Wittchen, HU (1996). Depression co-morbid with anxiety : results from the WHO study on psychological disorders in primary health care. British Journal of Psychiatry 168 (Suppl. 30), 38-43.

Sauer WH, Berlin JA, Kimmel SE (2001). Selective serotonin reuptake inhibitors and myocardial infarction. Circulation 104, 1894-1898.

Simon GE, Lin EH, Katon W, Saunders K, VonKorff M, Walker E, Bush T, Robinson P (1995). Outcomes of 'inadequate' antidepressant treatment. Journal of General Internal Medicine 10, 663-670.

Simon GE, VonKorff M, Lin E (2005). Clinical and functional outcomes of depression treatment in patients with and without chronic medical illness. Psychological Medicine 35, 271-279.

Stein MB, Cox BJ, Afifi TO, Belik S.-L, Sareen J (2006). Does co-morbid depressive illness magnify the impact of chronic physical illness? A population-based perspective. Psychological Medicine 36, 587-596.

Steiner JF, Prochazka AV (1997). The assessment of refill compliance using pharmacy records: methods, validity, and applications. Journal of Clinical Epidemiology 50, 105116.

Taylor CB, Youngblood ME, Catellier D, Veith RC, Carney RM, Burg MM, Kaufmann PG, Shuster J, Mellman T, Blumenthal JA, Krishnan R, Jaffe AS (2005). Effects of antidepressant medication on morbidity and mortality in depressed patients after myocardial infarction. Archives of General Psychiatry 62, 792-798.

Unutzer J, Katon W, Callahan CM, Williams Jr. JW, Hunkeler EHarpole L, Hoffing M, Della Penna RD, Noel PH, Lin EH, Tang L \& Oishi S (2003). Depression treatment in a sample of 1,801 depressed older adults in primary care. Journal of the American Geriatrics Society $51,505-514$.

Unutzer J, Simon G, Belin TR, Datt M, Katon W, Patrick D. (2000). Care for depression in HMO patients aged 65 and older. Journal of the American Geriatrics Society 48, 871-878.

Van den Akker M, Schuurman A, Metsemakers J, Buntinx F (2004). Is depression related to subsequent diabetes mellitus? Acta Psychiatrica Scandinavica 110, 178-183.

Van Marwijk HWJ, Grundmeijer HGLM, Bijl D, Van Gelderen MG, De Haan M, Van WeelBaumgarten EM, Burgers JS, Boukes FS, Romeijnders ACM (2003). The Dutch College of 
Nuyen, J., Spreeuwenberg, P.M., Dijk, L. van, Bos, G.A.M. van den, Groenewegen, P.P., Schellevis, F.G.

The influence of specific chronic somatic conditions on the care for co-morbid depression in general practice.

Psychological Medicine: 2008, 38(2), 265-277

General Practitioners (NHG) Practice Guideline 'Depression', first revision [in Dutch]. Huisarts en Wetenschap 46, 614-633.

Van Melle JP, De Jonge P, Spijkerman TA, Tijssen JG, Van Veldhuisen DJ, Van den Brink $\mathrm{RH}$, Van den Berg MP (2004). Prognostic association of depression following myocardial infarction with mortality and cardiovascular events : a meta-analysis. Psychosomatic Medicine 66, 814-822.

Westert GP, Schellevis FG, De Bakker DH, Groenewegen PP, Bensing JM, Van der Zee J (2005). Monitoring health inequalities through general practice : the Second Dutch National Survey of General Practice. European Journal of Public Health 15, 59-65.

WHO (2006). Collaborating Centre for Drug Statistics Methodology. Norwegian Institute of Public Health (www.whocc.no). Accessed 15 May 2006.

Whooley MA, Simon GE (2000). Managing depression in medical outpatients. New England Journal of Medicine 343, 1942-1950.

WONCA Classification Committee (1983). International Classification of Health Problems in Primary Care (ICHPPC-2-Defined). Oxford University Press : Oxford.

Zhang X, Norris SL, Gregg EW, Cheng YJ, Beckles G, Kahn, HS (2005). Depressive symptoms and mortality among persons with and without diabetes. American Journal of Epidemiology 161, 652-660.

\section{APPENDIX}

ICPC diagnoses included in the categories of specific chronic somatic morbidity

\begin{tabular}{|c|c|}
\hline $\begin{array}{l}\text { Chronic somatic } \\
\text { condition }\end{array}$ & ICPC diagnoses \\
\hline Colon & Diverticular disease, irritable bowel syndrome, or chronic enteritis/ulcerative colitis \\
\hline Stomach/duodenal & Duodenal or other peptic ulcer, or disorder of the stomach function \\
\hline Hypertension & Uncomplicated hypertension or hypertension with involvement of target organs \\
\hline Cardiac arrhythmia & Atrial fibrillation/flutter, paroxysmal tachycardia, or ectopic beats \\
\hline Ischaemic heart & Angina pectoris, acute myocardial infarction, other chronic ischaemic heart disease, or heart failure \\
\hline $\begin{array}{l}\text { Osteoarthritis/rheumatoid } \\
\text { arthritis }\end{array}$ & Osteoarthritis of spine/hip/knee, other osteoarthritis, or rheumatoid arthritis/allied condition \\
\hline Migraine & Migraine \\
\hline Neurological conditions & $\begin{array}{l}\text { Multiple sclerosis, Parkinson's disease/parkinsonism, epilepsy, dementia, or stroke/transient } \\
\text { ischaemic accident }\end{array}$ \\
\hline Chronic lung & Chronic bronchitis, emphysema, chronic obstructive pulmonary disease, or asthma \\
\hline Skin & Eczema or psoriasis \\
\hline Diabetes mellitus & Diabetes mellitus \\
\hline Thyroid & Hyperthyroidism, hypothyroidism, or goitre \\
\hline Cancer & Any malignant neoplasm ${ }^{a}$ \\
\hline
\end{tabular}

ICPC, International Classification of Primary Care (Lamberts \& Woods, 1987).

a Skin cancer was excluded because of supposed lack of chronicity. 